\title{
Advanced liquid epoxy and polyurethane materials: internal and external coatings for pipeline and tubing protection
}

\author{
Andrey Keresten ${ }^{1, *}$, Stepan Ostanin ${ }^{1,2}$, and Vyacheslav Zuev ${ }^{1,2,3}$ \\ ${ }^{1}$ JSC CRONOS SPb, 197183, Saint-Petersburg, Russia \\ ${ }^{2}$ ITMO University, 197101, Saint-Petersburg, Russia \\ ${ }^{3}$ Institute of Macromolecular Compounds Russian Academy of Science, 199004, Saint-Petersburg, Russia
}

\begin{abstract}
The paper discusses anticorrosive materials developed by JSC "CRONOS SPb" for different application for oil/gas industry. A series of coatings were tested for compliance with industrial Russian and international standards. Epoxy KronEpur 80 and KronEpur NKT coatings for the internal surfaces of pipelines and tubing with high Tg comply with Russian state standard GOST 58346. KronTag developed for RFID tags protection meet the requirements for internal coatings according GOST 58346. Hybrid epoxyurethane coating Eton-SAP has extremely low operational thickness. Repairing material Polykron-R tested by DIN EN 10290.
\end{abstract}

\section{Introduction}

One of the most significant factors that affect the technical condition of oil and gas equipment is corrosion [1]. Corrosion protection of pipelines, valves and fittings is achieved, by the application of protective anticorrosive coatings [2]. There are several types of anticorrosive coatings, which are most widely used in industry. The main types used for buried or submerged pipelines are liquid paint coatings (epoxy or polyurethanes (PU)), extrusion-applied triple layer coatings with epoxy powder and two layers of polyethylene or polypropylene, plastic tape coatings (PVC, polyester or polyethylene) and polyurethane foam coatings (which provide corrosion protection with thermal insulation). Each approach have their advantages and disadvantages. Hence, the determination of the most convenient and reliable coating is a crucial task for oil and gas industry [3].

The selection of appropriate material is the main challenge. For example, epoxy powder systems require complicated and expensive devices for high temperature treatment. Liquid epoxy coatings require long curing time. PU coatings have excessively high thickness. It is clear that the desirable coating should possess cheap and fast application and provide long lasting anticorrosion protection. Sometimes that might be achieved only by combination of materials with different chemistry.

In that paper we present developed by us liquid epoxy, modified PU and hybrid epoxy/urethane coating that are solve existing problems. A pair of modified liquid epoxy materials for internal anticorrosive coatings of pipes and tubings were designed. Several PU coatings were developed to protect external surface of pipes, fittings and valves. Special coating for protection of Radio Frequency Identification (RFID) tags was tested.

\section{Liquid epoxy coatings}

The fusion-bonded epoxy (FBE) is the most commonly applied coating. Typical FBE application process involves many different complex stages. All of them should be completed correctly. It requires preheating, chromate treatment, reheating, FBE application and quenching steps. Preheating stage and following pipe heating where the contents of the powder melt and transform to a liquid form is usually performed in the temperatures range of $180{ }^{\circ} \mathrm{C}$ to $250{ }^{\circ} \mathrm{C}\left(360{ }^{\circ} \mathrm{F}\right.$ to 480 $\left.{ }^{\circ} \mathrm{F}\right)$. Weakening of the pipe wall structure is possible if heating temperature limits are exceeded [4]. A nonconforming system will result if chromate application processes are not exact. Each production steps in the process has further potential for error and thus failure.

KronEpur 80 and KronEpur NKT liquid epoxy coatings based on accelerated cycloaliphatic amine adduct were developed to overcome these disadvantages. The lower difficulty in the application process of liquid epoxy not only reduces the chances of error but also reduces the complexity of a laborious process and steps involved in quality assurance.

We estimate thermal characteristics of designed twocomponent epoxy coatings by differential scanning calorimetry (DSC). The DSC was performed with NETZCH DSC 204 F1 Phoenix. Figure 1 illustrates the DSC curves of KronEpur 80. The bottom line (green) is referred to first heating and the upper (purple) to second heating.

* Corresponding author: ovnt@,lkz-kronos.ru 


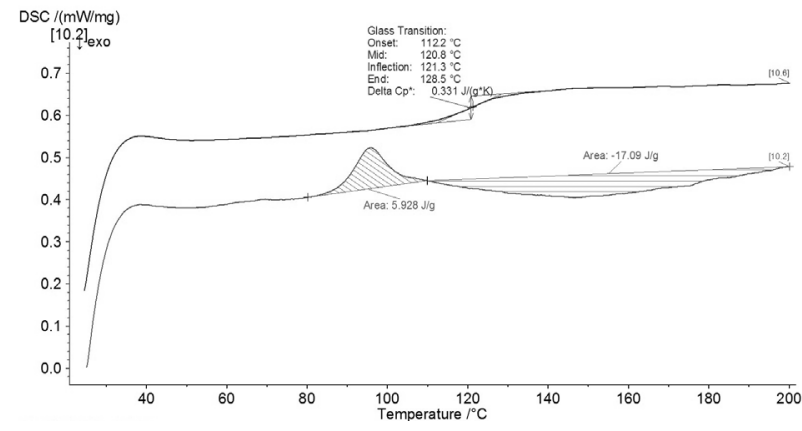

Fig. 1. DSC curves of KronEpur 80.

The average resultant values of glass-transition temperature $(\mathrm{Tg})$ were more than $120{ }^{\circ} \mathrm{C}$ that are higher than for similar liquid epoxies and fairly close to FBE coating systems [5]. At the $80-112{ }^{\circ} \mathrm{C}$ curing of the coating can be observed.

Another series of tests including resistance to aggressive environments, decompression and autoclave tests were carried out. The results show the compliance of KronEpur 80 and KronEpur NKT with GOST 583462019 'Steel pipes and fittings for oil industry. Inner surface protective paint. General technical requirements.' The possibility of their exploitation at 80 ${ }^{\circ} \mathrm{C}$ was confirmed. The results of the tests are given in Table 1.

Table 1. GOST R 58346-2019 compliance results.

\begin{tabular}{|c|c|c|}
\hline Test & $\begin{array}{l}\text { Coating } \\
\text { surface }\end{array}$ & Adhesion \\
\hline $\begin{array}{l}\text { Autoclave test in a } 5 \% \mathrm{NaCl} \\
\text { solution under }(2,0 \pm 0,2) \\
\mathrm{MPa} \mathrm{CO}_{2} \text { and }(3,0 \pm 0,3) \mathrm{MPa} \\
\mathrm{N}_{2} \text { at a temperature of } \\
(80 \pm 3){ }^{\circ} \mathrm{C} \text { for } 240 \text { hours }\end{array}$ & Unchanged & $11 \mathrm{MPa}$ \\
\hline $\begin{array}{l}\text { Autoclave test in a } 5 \% \mathrm{NaCl} \\
\text { solution under }(1,0 \pm 0,1) \\
\mathrm{MPa} \mathrm{H}_{2} \mathrm{~S} \text { and }(4,0 \pm 0,4) \mathrm{MPa} \\
\mathrm{N}_{2} \text { at a temperature of } \\
(80 \pm 3){ }^{\circ} \mathrm{C} \text { for } 240 \text { hours }\end{array}$ & Unchanged & $11 \mathrm{MPa}$ \\
\hline $\begin{array}{l}\text { Immersion in a } 10 \% \mathrm{HCl} \\
\text { solution at a temperature of } \\
(50 \pm 3){ }^{\circ} \mathrm{C} \text { for } 24 \text { hours }\end{array}$ & Unchanged & $13 \mathrm{MPa}$ \\
\hline $\begin{array}{l}\text { Temperature cycling test } \\
\text { with a high temperature of } \\
(60 \pm 3){ }^{\circ} \mathrm{C} \text { and a low } \\
\text { temperature of }-(60 \pm 3){ }^{\circ} \mathrm{C} \text {, } \\
15 \text { cycles }\end{array}$ & Unchanged & $14 \mathrm{MPa}$ \\
\hline $\begin{array}{l}\text { Immersion in petroleum } \\
\text { products simulator (xylene } \\
\text { and toluene in volume ratio } \\
\text { of } 1: 1) \text { at a temperature of } \\
(20 \pm 3){ }^{\circ} \mathrm{C} \text { for } 1000 \text { hours }\end{array}$ & Unchanged & $12 \mathrm{MPa}$ \\
\hline
\end{tabular}

In combination with autoclave tests appearance rating tests and pull-off tests for adhesion were performed according GOST 9.407 and GOST 32299 respectively. Default value of adhesion was $11 \mathrm{MPa}$. Results confirmed accordance of KronEpur 80 coating for inner surface of steel pipes and fittings for oilfield pipelines, and accordance of KronEpur NKT coating for oilfield equipment tubing.

Application of these materials is carried out by airless spraying units and is more cost-effective than application of FBE due to the heating of the coating at lower temperatures. Figure 2 represent an inner surface of a pipe coated with KronEpur 80.

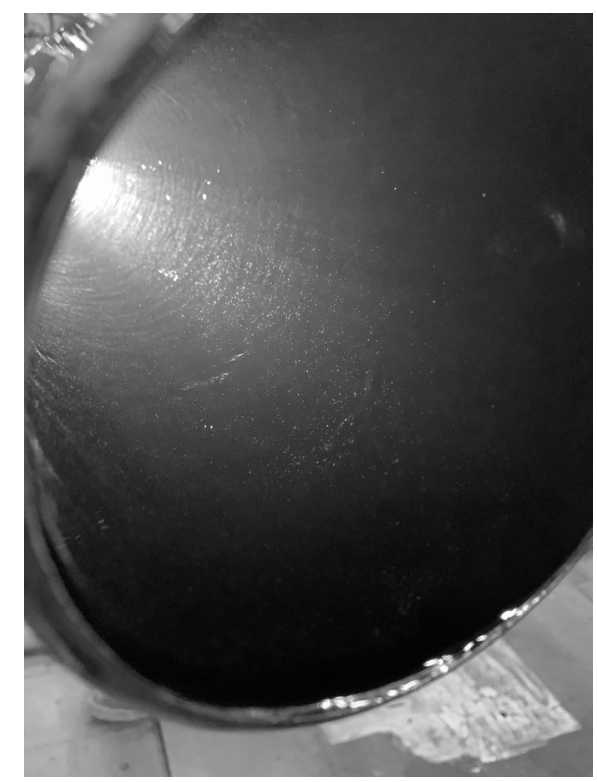

Fig. 2. An inner surface of a pipe coated with KronEpur 80 .

Now we are working with the chemical composition of liquid epoxies in order to improve their properties and ensure that they can withstand exploitation temperature of $120^{\circ} \mathrm{C}$.

\section{Hybrid epoxy-urethane coatings}

\subsection{Thin-layer epoxy-urethane coating}

The use of epoxy resins is limited due to their high brittleness and low impact resistance. That might be overcome by addition of elastomers. A combination of epoxy and urethane can improve the anticorrosion performance as well as provide the balance of overall properties.

In the present work, we have modified urethane elastomer by epoxy resin. The synergy effect of such combination gives the unique properties of resulting Eton-SAP material. It was tested on physical-mechanical properties and compared with the average values for epoxy and PU coatings. The adhesion of the PU coating to stainless steel was evaluated by pull-off strength measurements carried out following the ASTM D4541 standard for coatings. The mechanical properties of the PU were measured by stress-strain tests carried out using a dogbone test specimen prepared according to the ISO 37 (ISO 2005) standard. The stress-strain tests were carried out using Shimadzu AGS-X testing machine 
provided with a mechanical extensometer at a pulling rate of $50 \mathrm{~mm} / \mathrm{min}$. Five replicates were measured and averaged. The results are given in table 2 .

Table 2. Physical-mechanical properties of Eton-SAP in comparison with epoxy and PU coatings [6,7].

\begin{tabular}{|c|c|c|c|}
\hline Parameter & $\begin{array}{c}\text { Liquid epoxy } \\
\text { coatings }\end{array}$ & $\begin{array}{c}\text { PU } \\
\text { coatings }\end{array}$ & Eton-SAP \\
\hline $\begin{array}{c}\text { Thickness, } \\
\text { mm }\end{array}$ & 1 & 3 & 1 \\
\hline $\begin{array}{c}\text { Adhesion to } \\
\text { steel, MPa }\end{array}$ & 12,5 & 12 & 12.9 \\
\hline $\begin{array}{c}\text { Dry to } \\
\text { handle, min }\end{array}$ & 180 & 15 & 15 \\
\hline $\begin{array}{c}\text { Tensile } \\
\text { elongation, \% }\end{array}$ & 15 & 26 & 25 \\
\hline $\begin{array}{c}\text { Tensile } \\
\text { strength, MPa }\end{array}$ & 14 & 9 & 29.7 \\
\hline
\end{tabular}

It might be seen that Eton-SAP has better physicalmechanical properties than epoxy and PU on the market. The major advantage of developed material is its low operational thickness. It requires less volume of material and helps to reduce losses when applied by airless spraying system. Fast cure time allows quick operational commissioning of coated product. Additionally, PU do not require primers or adhesives. They are applied directly to the steel substrate, giving rise to more adhesion and fewer chances of delamination. Eton-SAP comply with STO Gazprom 9.1-018-2012.

\subsection{Epoxy-urethane coating for RFID tags protection}

Another task is protection of Radio Frequency Identification tags that are located on the external surface of the pipes. According to the industry requirements, tags should be protected by a coating that comply with the specifications for internal protection coatings. Nevertheless, internal coatings in most cases are very specific and it is hard task to readjust them for external use.

That is where remarkable properties of hybrid epoxypolyurethanes are implemented. Specifically designed for RFID tags protection KronTag coating was tested for compliance with GOST R 58346-2019. The coating is fast-curing with set up time of 1 minute. It also does not require any temperature treatment after applying.

Figure 3 represent KronTag coated specimens after 240 hours autoclave test with 10 minutes decompression in $\mathrm{H}_{2} \mathrm{~S}(\mathrm{a})$; after 24 hours autoclave test with explosive decompression (1,5 seconds) in $\mathrm{CO}_{2}(\mathrm{~b})$.

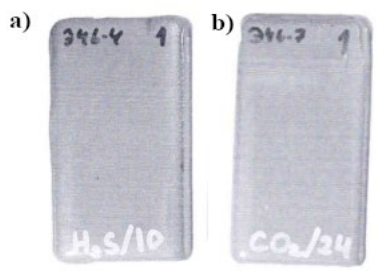

Fig. 3. Surface of KronTag coated specimens after autoclave tests.
After autoclave tests the coating did not have cracks, delamination, or a decrease in adhesion.

\section{PU coating of manual application}

An extremely important advantage of PU coatings over other traditional coatings is their fast curing time. Most PU set up very quickly, within seconds or minutes of application due to use of aromatic diisocyanates such as toluene diisocyanate (TDI), methylenediphenyl diisocyanate (MDI) and their oligomers.

Repairing polyurethane coating Polykron-R has been developed and tested for compliance with GOST DIN EN 10290 and Gazprom and Transneft requirements. Use of aliphatic hexamethylene diisocyanate (HDI) in the composition allowed to increase curing time of mastic, provided with possibility of manual application and retained anti-corrosion properties of PU.

Cathodic disbondment test was performed for 1000 hrs in $3 \% \mathrm{NaCl}$ with the saturated calomel electrode potential of $-1500 \mathrm{mV}$. Steel plate with Polykron-R coating after cathodic disbondment test is presented on Figure 4.

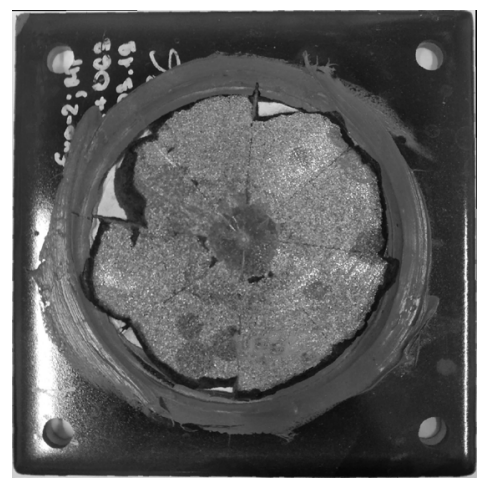

Fig. 4. Steel plate with Polykron-R coating after cathodic disbondment test. Area of disbondment (circle of rust) can be seen in the center of the plate.

Specific electrical insulation resistance test was carried out for $1000 \mathrm{hrs}$ in $3 \% \mathrm{NaCl}$ at $60{ }^{\circ} \mathrm{C}$. The values of measured resistance stabilized at $10^{9} \Omega$ that is higher than required $10^{7} \Omega$ (Figure 5).

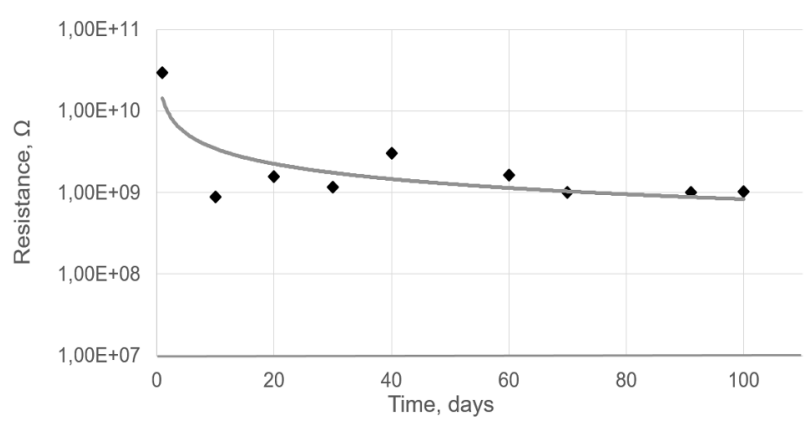

Fig. 5. Specific electrical insulation resistance curve of Polykron-R. 
Table 3. Physical-mechanical properties of Polykron-R in comparison with airless applying systems.

\begin{tabular}{|l|c|c|c|c|c|c|}
\hline Material & Application & $\begin{array}{c}\text { Set up time, } \\
\text { min }\end{array}$ & $\begin{array}{c}\text { Adhesion to steel, } \\
\mathrm{MPa}\end{array}$ & $\begin{array}{c}\text { Tensile strength, } \\
\mathrm{MPa}\end{array}$ & $\begin{array}{c}\text { Tensile } \\
\text { elongation, } \%\end{array}$ & $\begin{array}{c}\text { Area of cathodic } \\
\text { disbondment after } 1000 \\
\mathrm{hrs} \text { in } 3 \% \mathrm{NaCl}\end{array}$ \\
\hline Polykron-R & Manual & 45 & 12 & 25 & 31 & 5,7 under $60^{\circ} \mathrm{C}$ \\
\hline Forpol-60 & Airless & 1 & 14,9 & 35 & 23,2 & 4,5 under $60^{\circ} \mathrm{C}$ \\
\hline Forpol-80 & Airless & 1 & 15,3 & 35 & 21 & 4,9 under $80^{\circ} \mathrm{C}$ \\
\hline
\end{tabular}

The table 3 presents results of tests of Polykron-R in comparison with typical PU-coatings Forpol-60 and Forpol-80 that are EU certified materials widely used by Gazprom and Transneft companies.

It can be seen that Polykron-R properties are close to those of airless applied materials. The use of manual application reduces the consumption of components, which makes it more economical than spraying application.

The main purpose of this coating is quick repair of damaged or poorly coated local areas on a pipe surface. As it does not require special airless spraying unit for application the coating might be easily applied on problem areas by repair crew while maintenance. Polykron-R coating comply with STO Gazprom 9.1-0182012.

\section{Conclusion}

New materials studied in the article represent technological solutions to the problem of corrosion of the internal and external surfaces of oilfield equipment and meet the necessary requirements of regulatory documents.

Liquid epoxy coatings KronEpur 80 and KronEpur NKT materials with improved Tg and KronTag coating for RFID tags protection comply with GOST R 583462019 requirements. They have distinct advantage over epoxy powder systems as they do not require high temperature treatment and applied by airless spraying unit.

Low operational thickness has been achieved by use of hybrid epoxy-urethane Eton-SAP. This reduces the material consumption and lower the operating costs of anticorrosion coating.

Manual application coating Polykron-R has proved compliance with DIN EN 10290. It does not require heavy and expensive spraying units for application and can be applied by pipeline repair crew while maintenance.

Internal coatings for the oil pipelines protection remain promising areas for the development of new coatings. Taking into consideration properties of Russian oil that is mostly a heavy oil with different contaminants, saturates, aromatics, resins and asphaltenes (SARA); we are working to create new low surface energy coating that prevents SARA precipitation on the tubing walls. The second important task is to increase $\mathrm{Tg}$ of the composition for internal coatings that rise its exploitation temperature to $120^{\circ} \mathrm{C}$.
We are thankful to NPC SAMARA and Peter the Great St.Petersburg Polytechnic University for testing the provided coatings for compliance with the necessary requirements.

\section{References}

1. Q. Okasha, A. Aladasani, A. Ameen, N. Aravid, K. Sen, M. Al-Dushaishi, Society of Petroleum Engineers, Paper No. 186208 (2017)

2. N. Sangaj, V. Malshe, Progress in Organic Coatings, 50 (1), 28-39 (2004)

3. A. Samimi, International Journal of Innovation and Applied Studies. 1. 186-193 (2012)

4. E. Aksu, Thermosets (Second Edition), 453-476 (2018)

5. W. Zhou, T. Jeffers, O. Decker, Materials Performance, 46 (4), 36-40, paper 07688 (2007)

6. O. Knudsen, A. Bjorgum, M. Polanco-Loria, R. Johnsen, NACE - International Corrosion Conference Series (2007)

7. Shiwei William Guan, Corrosion NACE Expo, paper 03043 (2003) 